\title{
Gene therapy strategies for treating brain tumors: Retroviruses are still good candidates for therapeutic vectors
}

\author{
Toshio Yawata, Keiji Shimizu \\ Department of Neurosurgery, Kochi Medical School, Nankoku, Japan \\ Email: kshimizu@kochi-u.ac.jp
}

Received 27 March 2013; revised 28 April 2013; accepted 15 May 2013

Copyright (C) 2013 Toshio Yawata, Keiji Shimizu. This is an open access article distributed under the Creative Commons Attribution License, which permits unrestricted use, distribution, and reproduction in any medium, provided the original work is properly cited.

\begin{abstract}
Glioblastoma multiforme (GBM) is the most common and aggressive primary brain tumor in adults. In the past few decades, many efforts have been made to improve the prognosis of GBM, however, with limited success. Many gene therapy strategies for GBM have been developed and a few have progressed to clinical trials. Retroviral vectors have superior features for gene therapy in brain cancers, including tumor specificity, immunogenicity, and longer half-life. Early gene therapy trials in GBM patients based on transplantation of retrovirus-producing cells into the brain failed to prove efficacious. Adenoviral vectors, which can be prepared as high-titer virus solutions and undergo efficient transduction in tumor cells, failed in clinical trials, likely due to immunogenicity and instability of gene expression. Alternative therapeutics such as oncolytic viruses that specifically target and destroy cancer cells are currently under investigation. In addition to novel vectors, retroviral vectors are still attractive candidates for use in gene therapy against brain tumors. Since yields of properly-packaged viral particles from virus-producing cells have been very limited so far, gene therapy by direct injection of hightiter retroviral vectors into the patients' brains was not possible. To overcome these disadvantages, a packaging cell line that yields high-titer retroviral solutions was established by our group, enabling the direct injection of massive retroviral vector stocks directly into the brain. Mouse glioma models were effectively cured with a combination of a suicide gene/ prodrug system and a highly-concentrated retrovirus solution. Preclinical assessments, including that of replication-competent retroviruses and tumorigenicity of the combination method, have confirmed the safety of the highly-concentrated retrovirus solution. Addi-
\end{abstract}

tional studies are needed to address the clinical utility of such combination gene therapies. Taken together, these data suggest that retroviral vectors are still good candidates for development in gene therapy applications.

Keywords: Gene Therapy; Malignant Glioma; Hsvtk; Retrovirus Vector; Bystander Effect

\section{CURRENT THERAPY FOR GLIOBLASTOMA}

Glioblastoma multiforme (GBM) is the most common and most aggressive malignant primary brain tumor in adults. Despite aggressive surgical resection coupled with optimized radiation and chemotherapy, GBM patients carry one of the worst prognoses and the median survival is 12 to 15 months [1-3]. The resistance to treatment and highly invasive property are representative biological features of GBM that prohibit improvements in the prognosis after conventional therapies. The current standard of care for GBM patients includes maximum surgical resection combined with radiation and concomitant and adjuvant temozolomide (TMZ) therapy [4]. Even with this multimodal therapy, extension of the median survival is only two to three months. Due to the poor prognosis despite the use of multimodal therapy, there is an urgent need for the development of effective novel therapies. Gene therapy is becoming a promising therapeutic alternative among of the many strategies explored for GBM.

\section{GENE THERAPY STRATEGY FOR MALIGNANT TUMORS}

Gene therapy is a technique for correcting defective genes responsible for disease development or for remov- 
ing malignant cells by killing these cells. Viral vectors are used to transfer the therapeutic genes into the target cells or tissues in patients. In gene therapy for congenital disorders, most of the gene sequence is used to supplement or alter the defective function. The first clinical trial of gene therapy for a genetic disorder was performed on patients with adenosine deaminase severe combined immunodeficiency (ADA-SCID) [5]. The absent or mutated adenosine deaminase in this disease was delivered by retroviral vector ex vivo to complement this enzyme. Contrary to the case of congenital disorders, it is not easy to obtain the therapeutic efficacy by transfer of correct genes into malignant tumors. A small number of nontransduced cells contribute to tumor recurrence by escaping the therapy. One of the most challenging problems in gene therapy is gene delivery. Low transduction rate of therapeutic genes leads an ineffective treatment, especially in gene therapy for malignant tumor [6]. Gene therapy by transfer of correct genes into tumors requires a higher rate of transduction to kill most tumor cells and current transduction methods are inadequate for eradication of metastatic or highly invasive tumors. The low transduction rate can be partially resolved by development of "suicide" gene therapy using a combination of toxic genes and prodrugs [7]. Suicide gene therapy capitalizes on the so-called "Bystander effect", a phenomenon in which toxic metabolites derived from the prodrug are transferred from the transduced cells expressing the toxic gene to neighboring non-transduced cells via gap junctions; this effect is recognized as a critical component that helps obtain therapeutic efficacy with suicide gene therapy [8]. In fact, we and others reported that suicide gene therapy had a transduction rate as high as $10 \%$ $70 \%$ and induced effective tumor regression in experimental models of brain cancer [9-11]. The basic principle of many gene therapies for malignant tumors is based on this mechanism and the use of viral vectors for gene delivery.

\section{FIRST GENE THERAPY FOR GBM USING RETROVIRUS-PRODUCING CELLS}

Gene therapy for glioma patients was initiated in 1992 at the National Institute of Health in United States [12]. This clinical trial was based on suicide gene therapy, which utilizes the combination of the herpes simplex virus thymidine kinase (HSVtk) gene and the prodrug ganciclovir (GCV). It is now a well-known strategy and its efficacy has been confirmed [13-15]. The bystander effect can be induced by optimizing the timing of GCV administration and therapeutic efficacy is increased in this system. The strategy of the clinical trial consists of GCV administration and the transduction of retrovirus vector harboring HSVtk gene, which induces the conver- sion of GCV to toxic metabolites. However, the retroviral titer was unfortunately too low in the clinical trial; therefore, virus-producing cells (VPCs) were transplanted into the tumor cavity to increase the transduction efficiency (Figure 1). This modified gene therapy was then applied to phase III clinical trials, but failed to provide efficacy [6]. One reason for the failure of this gene therapy is caused by the low transduction rate, probably caused by the low potential of VPCs to produce the retrovirus and the instability of the xenotransplanted mouse VPCs in humans.

\section{SUICIDE GENE THERAPY BY THE INJECTION OF ADENOVIRAL VECTOR INTO THE WALL OF THE TUMOR CAVITY}

Adenoviral vectors have been widely used in gene therapy studies [16]. Because the genome of adenoviruses consists of a linear double-stranded DNA genome, the stability of the virus is relatively high, which allows for the preparation of high-titer virus solutions. Adenoviruses are able to transduce both dividing and non-dividing cells. In experiments, including those in which intracranial injection was sued for transplantation of retroviral VPCs or adenovirus, much higher transduction rates were found in some areas of tumors in mice treated with an adenoviral vector [17]. However, an important limitation in the use of adenoviral vectors has been the difficulty in obtaining expression stability, because the viral genome fails to replicate in the transduced cells.

Adenoviral vectors were adapted to improve the transduction rate in clinical trials of suicide gene therapy using HSVtk [18-22]. In these clinical trials, adenoviruses were injected multiple times into healthy brain tissues in the tumor cavity following surgical removal of the solid tumor mass, which was then followed by GCV administration (Figure 1). An improvement in the median survival period of glioma patients treated with this vector has been reported [22]. The assessment of the safety of this suicide gene therapy was performed by serological assessment, i.e., routine blood and urine analysis and the detection of anti-adenoviral antibodies. These assessments indicated that the therapy was well-tolerated and no major alterations in routine laboratory test results were observed. Recently, Ark Therapeutics completed three clinical trials with Cerepro, based on an adenovirus-mediated HSVTk gene therapy, and reported significant efficacy in recent phase III trials [23]. However, the European Medicines Agency (EMA) has denied approval for Cerepro and further trials are required to meet regulatory requirements for approval [23].

\section{ONCOLYTIC VIRAL THERAPY}

Oncolytic viral vectors are based on the capacity of vac- 
Early clinical trial of gene therapy by VPC transplantation

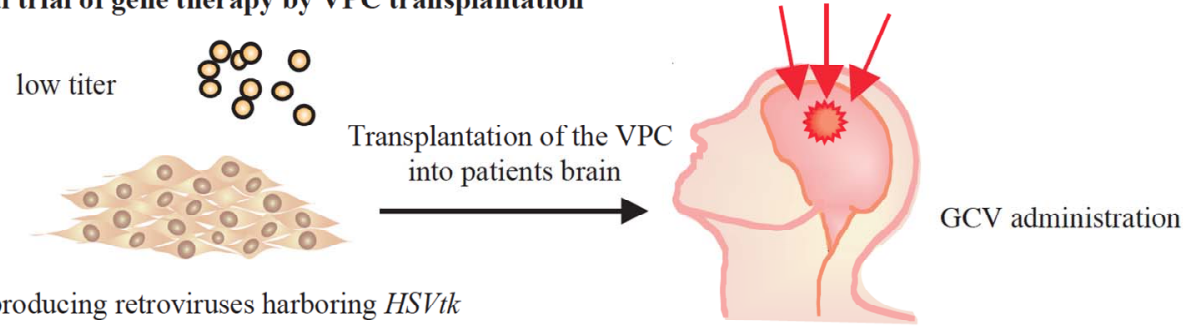

Clinical trials by injection of adenovirus vector (Cerepro) into brain tissues

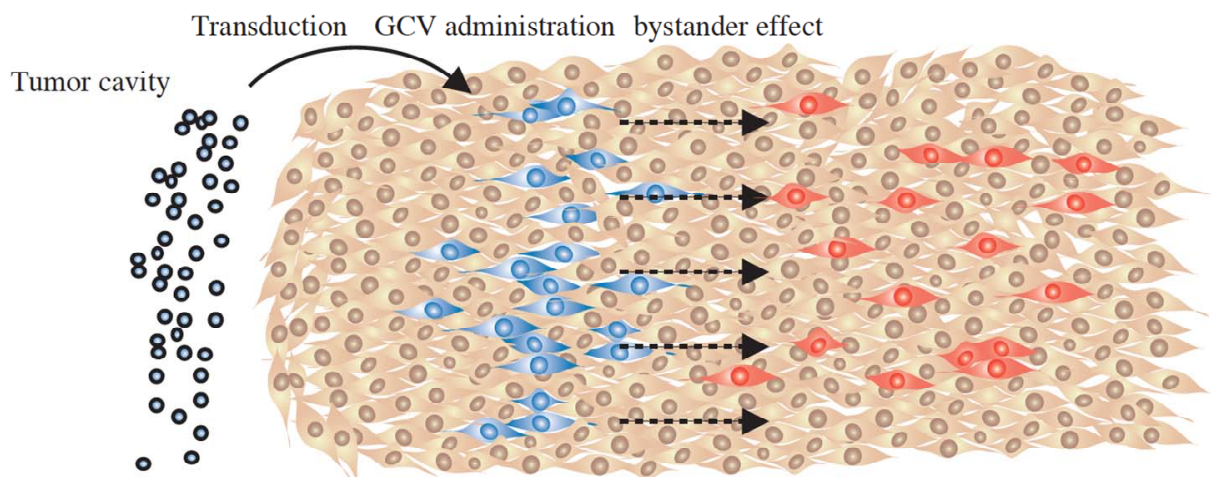

Adenovirus harboring HSVtk Normal or tumor cells Tumor cells invading into brain tissue producing GCV-MP, -DP, -TP

Gene therapy with direct injection of highly concentrated retrovirus solution

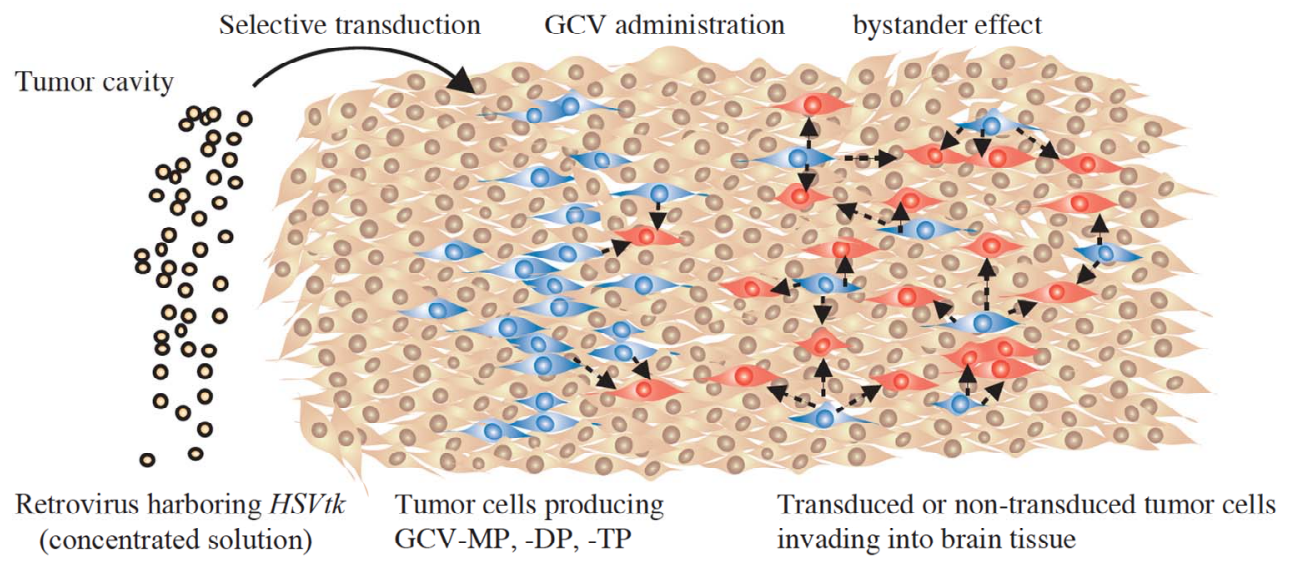

Figure 1. Strategy of suicide gene therapy against glioblastoma. Upper, First clinical trial for glioma patients held in 1991 at the National Institute of Health, USA. VPCs producing HSVtk-carrying retrovirus were transplanted into the patient's brain, followed by GCV administration. Middle, Adenoviruses harboring HSVtk are injected into the wall of the tumor cavity, formed after the removal of the tumor mass. Transduced normal or tumor cells surrounding the cavity converted the GCV to GCV-monophosphate (GCV-MP) via the catalytic activity of HSVtk. GCV-MP was converted to GCV-diphosphate (GCV-DP) and then finally to GCV-triphosphate (GCV-TP) by endogenous kinases inside transduced cells. GCV-TP inhibits DNA synthesis and leads to cell death. Because GCV-MP, GCV-DP, and GCV-TP disperse to neighboring cells through gap junctions, the non-transduced cells are also killed by this bystander effect. Tumor-specific cell death is based on the differential sensitivity to GCV-TP. Most normal cells that are no longer undergoing cell division are not affected by GCV-TP. Contrary to this, dividing tumor cells are susceptible to GCV-TP-induced apoptosis due to inhibition of DNA synthesis. Bottom, A highly-concentrated retrovirus solution is injected into the wall of the tumor cavity, followed by GCV administration. Retroviruses selectively transduce to the tumor cells in the brain and stably express HSVtk. By allowing transduced tumor cells to migrate and disperse into tumor tissues, non-transduced cells distant from the cavity can be effectively killed via the bystander effect. 
cinia, HSV, and Reo viruses to preferentially infect and lyse cancer cells [24]. Different from genetically engineered replication-incompetent retro- and adenoviral vectors, oncolytic viral vectors destroy tumor cells through specific replication in these cells and expression of antitumor genes encoded by the vector. After lysis of infected tumor cells, thousands of viral progeny are released and spread to neighboring tumor cells. Because of the replication-competence of these viruses, the virus dosage required to achieve therapeutic efficacy seems to be low, compared with retro and adenovirus vectors. In addition, oncolytic viral vectors can also stimulate anti-tumor immune responses [25,26]. The immune cells responsible for adaptive immunity are recruited to the site of the infection and participate in both the killing of virally infected cells and the production of antibodies against the foreign antigen, typically a tumor-specific antigen. In contrast, the innate immune system limits viral propagation, signals for maturation of antigen-presenting cells, and activates the adaptive immune response through antigen-specific $\mathrm{T}$ and $\mathrm{B}$ cell maturation. In recent years, clinical trials for glioma patients using oncolytic viral vectors have been performed and of these an HSV-based vector, HSV1716, has entered Phase III clinical trials in recurrent glioblastoma and we are currently awaiting the results.

\section{GENE THERAPY WITH DIRECT ADMINISTRATION OF A HIGH-TITER RETROVIRUS SOLUTION}

Due to a lower potential for viral particle production by retrovirus-packaging cells, clinical trials for malignant glioma by direct injection of retroviruses has never been performed. However, retroviral vectors have desirable features for use in gene therapy of malignant glioma. After retroviral infection, DNA reverse-transcribed from the retroviral RNA genome can integrate into the host genome only during mitosis. Brain tumor cells divide continuously, while most brain cells are differentiated and have ceased cell division. Thus, transduction and expression of toxic genes, driven by the integrated retroviral sequences, occurs only in tumor cells within the brain.

Stability of viral vectors in vivo during gene transfer is a major concern for achieving high transduction efficiency. It is well-known that retroviruses are inactivated by human serum due to the triggering of the classical complement cascade [27]. Contrary to this, one study found that there was no inactivation of retrovirus in the cerebrospinal fluid of patients with glioma or unrelated disorders [28]. These data suggest that gene transfer using retroviruses could be performed and directed into the tumor cavity after the removal of the tumor in glioma patients. To develop such a gene therapy, we established a retrovirus-producing cell line, PAMP51, that produces viruses (at a titer $>1 \times 10^{7} \mathrm{CFU} / \mathrm{mL}$ ) by introduction of the polyoma early region into the retroviral genome [29]. This method of virus production enables the injection of massive amounts of retrovirus directly into the patient's brain (Figure 1). If low-yield virus-producing cell lines, with titers of $\sim 1 \times 10^{6} \mathrm{CFU} / \mathrm{mL}$, were used for the therapy, more than a $100 \mathrm{~L}$ of virus solution would need to be administrated into the brain, to ensure that $1 \times 10^{11}$ retroviruses are administered to the same number of cells, found in a tumor mass of a diameter of $5 \mathrm{~cm}$. This is an unreasonable amount of viral solution to have to administer to patients. Thus, a highly-concentrated viral solution greatly improves the likelihood and successful use of direct retroviral injection-based gene therapy. We reported that retrovirus solution could be readily concentrated to $1 \times 10^{11-12} \mathrm{CFU} / \mathrm{mL}$ by using high-yield virusproducing cells and low-speed centrifugation [11]. Because the polyoma early region enhances transcription of the retroviral genome from long terminal repeat (LTR) promoter, the production of empty viral particles without the RNA genome is dramatically reduced in the culture supernatant of PAMP51 cells. Empty viral particles can occupy the retroviral receptor on target cells and obscure the transduction of retroviral vector; moreover, the viral solution cannot be concentrated easily when empty viral particles are dominant in the solution. Thus, the concentrated retroviral solution prepared from PAMP51 cell culture supernatant is of high purity and appears to be safe for use in gene therapy. To evaluate the efficacy of the suicide gene therapy by direct injection of a highlyconcentrated retrovirus solution, mouse glioma models were treated with the vector, followed by GCV administration [11]. In this model, the glioma was effectively cured by gene therapy using this technology. Also, bystander effects were considered to be most important factor for this gene therapy. The timing of the viral injection and GCV administration were scheduled to allow for the distribution of transduced cells in the tumor mass and maximization of induction via the bystander effect. Because the gene expression from the retroviral vector is very stable, even non-transduced cells distant from the tumor cavity were targeted via the bystander effect. In addition, the cells transduced with the retroviral vector have been suggested to prime the immune system. When mice once treated with the gene therapy were challenged again by subcutaneous injection of tumor cells, the growth of the tumor cells was completely suppressed [11]. Thus, not only does the reaction help reduce the tumor mass but it also has the potential to prevent tumor recurrence.

In clinical trials for X-linked severe combined immunodeficiency (SCID) using a retroviral vector [30], leukemia occurred due to the insertion of the retroviral 
genome at the proto-oncogene $L M O 2$ [31]. The clinical trials of gene therapy using retroviral vector were suspended in 2003. However, the efficacy of this gene therapy had been confirmed and the development of leukemia was restricted to the youngest patients in the trial. The clinical trials for this disease were allowed to resume, but were resuspended in the next year. In suicide gene therapy for tumors, leukemogenesis is unlikely to be a concern in most cases, since transduced cells are killed by GCV administration. Furthermore, retroviruses are readily inactivated in serum as described above; therefore, the incidence of retroviral infection in leukocytes in vivo is likely to be lower than in X-linked SCID treated using ex vivo gene therapy.

Another safety issue in gene therapy with direct administration of a high-titer retrovirus solution is with the use of replication-competent retroviruses (RCRs). The adverse effects of retroviral propagation in the human body are still not known. Because a large amount of retroviral vector needs to be administrated to patients in this gene therapy, the assessment of the effects of RCRs has been performed according to the strict regulations set forth in Good Laboratory Practice Regulations in many countries. No RCR was detected in our high-titer retrovirus vector. In addition, oncogenesis and other side effects were not induced by the injection of a highly concentrated retrovirus $\left(1 \times 10^{11} \mathrm{CFU}\right)$ into the brain of a primate model, the common marmoset, when assessed over 2 years [unpublished data]. Further tests are still needed to ensure the safety of this gene therapy.

Transcriptional targeting of tumor cells is ideal in suicide gene therapy to reduce the side effects against normal cells. Tissue- and cancer-specific gene promoters have been utilized for restricted expression of toxic genes [32-35]. In addition, the LTR promoter of retroviral vectors is occasionally inactivated in transduced cells. Because myelin basic protein (MBP) is mainly expressed in the brain, its promoter has been used to regulate HSVtk gene expression in retroviral vectors [32]. The combination of a retroviral vector and the brain-specific expression of HSVtk gene keeps normal cells in the brain from undergoing retroviral transduction-induced apoptosis. The SSX4 promoter was identified as a tumor-specific promoter, being active in most glioma cells and inactive in normal cells, and was used for controlling HSVtk expression in gene therapy [36]. The SSX4 gene is expressed in all glioma cell lines and the utilization of its promoter is likely to be effective in most of the glioma patients. These tissue-specific promoters facilitate tissueor tumor-specific gene therapy using viral vectors and ensure the safety of the therapy.

\section{CONCLUSION}

Many viral vectors have been developed to treat malig- nant glioma; however, current gene therapies are not sufficiently efficacious. Our strategy of gene therapy, using a high-titer retroviral vector, has advantages of both retroviral and adenoviral vectors. At present, retroviral vectors can be concentrated to $1 \times 10^{11-12} \mathrm{CFU} / \mathrm{mL}$ in our system. Moreover, high transduction rates can be achieved with retroviral and adenoviral vectors, ultimately leading to a higher efficacy of gene therapies. To perform clinical trials of this gene therapy for malignant glioma, preparation of large quantities of retroviral vectors is further required. Suspension cultures of VPCs were established to scale-up retroviral production. Improvements in retroviral production systems and confirmation of the safety and efficacy of suicide gene therapy will enable us to conduct clinical trials in and/or treat more patients.

\section{REFERENCES}

[1] DeAngelis, L.M., Gutin, P.H., Leibel, S.A. and Posner, J.B. (2002) Intracranial tumors: Diagnosis and treatment. Martin Dunitz, London, 367-394.

[2] Mahaley Jr., M.S., Mettlin, C., Natarajan, N., Laws Jr., E.R. and Peace, B.B. (1989) National survey of patterns of care for brain-tumo patients. Journal of Neurosurgery, 71, 826-836. doi:10.3171/jns.1989.71.6.0826

[3] Deen, D.F., Chiarodo, A., Grimm, E.A., Fike, J.R., Israel, M.A., Kun, L.E., Levin, V.A., Marton, L.J., Packer, R.J., Pegg, A.E., Rosenblum, M.L., Suit, H.D., Walker, M.D., Wikstrand, C.J., Wilson, C.B., Wong, A.J. and Yung, W.K. (1993) Brain tumor working group report on the 9th international conference on brain tumor research and therapy. Organ system program, National Cancer Institute. Journal of Neurosurgery, 16, 243-272. doi:10.1007/BF01057041

[4] Stupp, R., Hegi, M.E., Gilbert, M.R. and Chakravarti, A. (2007) Chemoradiotherapy in malignant glioma: Standard of care and future directions. Journal of Clinical Oncology, 25, 4127-4136. doi:10.1200/JCO.2007.11.8554

[5] Blaese, R.M., Culver, K.W., Miller, A.D., Carter, C.S., Fleisher, T., Clerici, M., Shearer, G., Chang, L., Chiang, Y., Tolstoshev, P., Greenblatt, J.J., Rosenberg, S.A., Klein, H., Berger, M., Mullen, C.A., Ramsey, W.J., Muul, L., Morgan, R.A. and Anderson, W.F. (1995) T lymphocyte-directed gene therapy for ADA-SCID: Initial trial results after 4 years. Science, 270, 475-480. doi:10.1126/science.270.5235.475

[6] Rainov, N.G. and Ren, H. (2003) Clinical trials with retrovirus mediated gene therapy-What have we learned? Journal of Neurooncology, 65, 227-236. doi:10.1023/B:NEON.0000003652.71665.f2

[7] Duarte, S., Carle, G., Faneca, H., de Lima, M.C. and Pierrefite-Carle, V. (2012) Suicide gene therapy in cancer: Where do we stand now? Cancer Letters, 324, 160-170. doi:10.1016/j.canlet.2012.05.023

[8] Bi, W.L., Parysek, L.M., Warnick, R. and Stambrook, P.J. (1993) In vivo evidence that metabolic cooperation is responsible for the bystander effect observed with HSVtk 
retroviral gene therapy. Human Gene Therapy, 4, 725731. doi:10.1089/hum.1993.4.6-725

[9] Culver, K.W., Ram, Z., Walbridge, S., Ishii, H., Oldfield, E.H. and Blaese, R.M. (1992) In vivo gene transfer with retroviral vector producer cells for treatment of experimental brain tumors. Science, 256, 1550-1552. doi:10.1126/science.1317968

[10] Yamada, M., Shimizu, K., Miyao, Y., Hayakawa, T., Ikenaka, K., Nakahira, K., Nakajima, K., Kagawa, T. and Mikoshiba, K. (1992) Retrovirus-mediated gene transfer targeted to malignant glioma cells in murine brain. Japan Journal of Cancer Research, 83, 1244-1247. doi:10.1111/j.1349-7006.1992.tb02752.x

[11] Tamura, K., Tamura, M., Ikenaka, K., Yoshimatsu, T., Miyao, Y., Nanmoku, K. and Shimizu, K. (2001) Eradication of murine brain tumors by direct inoculation of concentrated high titer-recombinant retrovirus harboring the herpes simplex virus thymidine kinase gene. Gene Therapy, 8, 215-222. doi:10.1038/sj.gt.3301371

[12] Ram, Z., Culver, K.W., Oshiro, E.M., Viola, J.J., DeVroom, H.L., Otto, E., Long, Z., Chiang, Y., McGarrity, G.J., Muul, L.M., Katz, D., Blaese, R.M. and Oldfield, E.H. (1997) Therapy of malignant brain tumors by intratumoral implantation of retroviral vector-producing cells. Nature Medicine, 3, 1354-1361. doi:10.1038/nm1297-1354

[13] Vincent, A.J., Vogels, R., Someren, V.G., Esandi, M.C., Noteboom, J.L., Avezaat, C.J., Vecht, C., Bekkum, D.W., Valerio, D., Bout, A. and Hoogerbrugge, P.M. (1996) Herpes simplex virus thymidine kinase gene therapy for rat malignant brain tumors. Human Gene Therapy, 7, 197-205. doi:10.1089/hum.1996.7.2-197

[14] Okada, H., Miyamura, K., Itoh, T., Hagiwara, M., Wakabayashi, T., Mizuno, M., Colosi, P., Kurtzman, G. and Yoshida, J. (1996) Gene therapy against an experimental glioma using adeno-associated virus vectors. Gene Therapy, 3, 957-964.

[15] Kramm, C.M., Chase, M., Herrlinger, U., Jacobs, A., Pechan, P.A., Rainov N.G., Sena-Esteves, M., Aghi, M., Barnett, F.H., Chiocca, E.A. and Breakefield, X.O. (1997) Therapeutic efficiency and safety of a second-generation replication-conditional HSV1 vector for brain tumor gene therapy. Human Gene Therapy, 8, 2057-2068. doi:10.1089/hum.1997.8.17-2057

[16] Gene Therapy Clinical Trials Worldwide (2013) Vectors used in gene therapy clinical trails. http://www.abedia.com/wiley/vectors.php

[17] Puumalainen, A., Vapalahti, M., Agrawal, R.S., Kossila, M., Laukkanen, J., Lehtolainen, P., Viita, H., Paljarvi, L., Vanninen, R. and Yla-Herttuala, S. (1998) Beta-galactosidase gene transfer to human malignant glioma in vivo using replication-deficient retroviruses and adenoviruses. Human Gene Therapy, 9, 1769-1774. doi:10.1089/hum.1998.9.12-1769

[18] Sandmair, A.M., Loimas, S., Puranen, P., Immonen, A., Kossila, M., Puranen, M., Hurskainen, H., Tyynela, K., Turunen, M., Vanninen, R., Lehtolainen, P., Paljarvi, L., Johansson, R., Vapalahti, M. and Yla-Herttuala, S. (2000) Thymidine kinase gene therapy for human malignant gli- oma, using replication-deficient retroviruses or adenoviruses. Human Gene Therapy, 11, 2197-2205. doi:10.1089/104303400750035726

[19] Trask, T.W., Trask, R.P., Aguilar-Cordova, E., Shine, H.D., Wyde, P.R., Goodman, J.C., Hamilton, W.J., Rojas-Martinez, A., Chen, S.H., Woo, S.L. and Grossman, R.G. (2000) Phase I study of adenoviral delivery of the HSV-tk gene and ganciclovir administration in patients with current malignant brain tumors. Molecular Therapy, 1, 195-203. doi:10.1006/mthe.2000.0030

[20] Eck, S.L., Alavi, J.B., Alavi, A., Davis, A., Hackney, D., Judy, K., Mollman, J., Phillips, P.C., Wheeldon, E.B. and Wilson, J.M. (1996) Treatment of advanced CNS malignnancies with the recombinant adenovirus H5.010RSVTK: A phase I trial. Human Gene Therapy, 7, 1465-1482. doi:10.1089/hum.1996.7.12-1465

[21] Germano, I.M., Fable, J., Gultekin, S.H. and Silvers, A. (2003) Adenovirus/herpes simplex-thymidine kinase/ganciclovir complex: Preliminary results of a phase I trial in patients with recurrent glioma. Journal of Neurooncology, 65, 279-289. doi:10.1023/B:NEON.0000003657.95085.56

[22] Smitt, P.S., Driesse, M., Wolbers, J., Kros, M. and Avezaat, C. (2003) Treatment of relapsed malignant glioma with an adenoviral vector containing the herpes simplex thymidine kinase gene followed by ganciclovir. Molecular Therapy, 7, 851-858. doi:10.1016/S1525-0016(03)00100-X

[23] Mitchell, P. (2010) Ark's gene therapy stumbles at the finish line. Nature Biotechnology, 28, 183-184. doi:10.1038/nbt0310-183

[24] Wollmann, G., Ozduman, K. and van den Pol, A.N. (2012) Oncolytic virus therapy for glioblastoma multiforme: Concepts and candidates. Cancer Journal, 18, 69-81. doi:10.1097/PPO.0b013e31824671c9

[25] De Siva, N., Atkins, H, Kirn, D.H., Bell, J.C. and Breitbach, C.J. (2010) Double trouble for tumors: Exploiting the tumour microenvironment to enhance anticancer effect of oncolytic viruses. Cytokine Growth Factor Review, 21, 135-141. doi:10.1016/j.cytogfr.2010.02.007

[26] Melcher, A., Parato, K., Rooney, C.M. and Bell, J.C. (2011) Thunder and lightning: Immunotherapy and oncolytic viruses collide. Molecular Therapy, 11, 13-21.

[27] Welsh Jr., R.M., Cooper, N.R., Jensen, F.C. and Oldstone, M.B. (1975) Human aserum lyses RNA tumour viruses. Nature, 257, 612-614. doi:10.1038/257612a0

[28] Shimizu, K., Miyao, Y., Tamura, M., Kishima, H., Ohkawa, M., Mabuchi, E., Yamada, M., Hayakawa, T. and Ikenaka, K. (1995) Infectious retrovirus is inactivated by serum but not by cerebrospinal fluid or fluid from tumor bed in patients with malignant glioma. Japan Journal of Cancer Research, 86, 1010-1012. doi:10.1111/j.1349-7006.1995.tb03013.x

[29] Yoshimatsu, T., Tamura, M., Kuriyama, S. and Ikenaka, K. (1998) Improvement of retroviral packaging cell lines by introducing the polyomavirus early region. Human Gene Therapy, 9, 161-172. doi:10.1089/hum.1998.9.2-161

[30] Hacein-Bey-Abina, S.F., Le Deist, F., Carlier, F., Boun- 
eaud, C., Hue, C., De Villartay, J., Thrasher, A.J., Wulffraat, N., Sorensen, R., Dupuis-Girod, S., Fischer, A., Davis, G., Kuis, W., Leiva, L. and Cavazzana-Calvo, M. (2002) Sustained correction of X-linked severe combined immunodeficiency by ex vivo gene therapy. New England Journal of Medicine, 346, 1185-1193. doi:10.1056/NEJMoa012616

[31] Hacein-Bey-Abina, S.C., von Kalle, M., Schmidt, M.P., McCormack, M.P., Wulffraat, N., Leboulch, P., Lim, A., Osborne, C.S., Pawliuk, R., Morillon, E., Sorensen, R., Foster, A., Fraser, P., Cohen, J.I., de Saint Basile, G., Alexander, I., Wintergerst, U., Frebourg, T., Aurias, A., Stoppa-Lyonnet, D., Romana, S., Radford-Weiss, I., Gross, F., Valensi, F., Delabesse, E., Macintyre, E., Sigaux, F., Soulier, J., Leiva, L.E., Wissler, M., Prinz, C., Rabbitts, T.H., Le Deist, F., Fischer, A. and Cavazzana-Calvo, M. (2003) LMO2-associated clonal $\mathrm{T}$ cell proliferation in two patients after gene therapy for SCID-X1. Science, 302, 415-419. doi:10.1126/science.1088547

[32] Miyao, Y., Shimizu, K., Tamura, M., Akita, H., Ikeda, K., Mabuchi, E., Kishima, H., Hayakawa, T. and Ikenaka, K. (1997) Usefulness of a mouse myelin basic protein promoter for gene therapy of malignant glioma: Myelin basic protein is strongly active in human malignant glioma cells. Japan Journal of Cancer Research, 88, 678-686. doi:10.1111/j.1349-7006.1997.tb00436.x

[33] Shinoura, N., Koike, H., Furitu, T., Hashimoto, M., Asai, A., Kirino, T. and Hamada H. (2000) Adenovirus-mediated transfer of caspase-8 augments cell death in gliomas: Implication for gene therapy. Human Gene Therapy, 11, 1123-1137. doi:10.1089/10430340050015185

[34] Shinoura, N., Saito, K., Yoshida, Y., Hashimoto, M., Asai, A., Kirino, T. and Hamada, H. (2000) Adenovirus-mediated transfer of bax with caspase- 8 controlled by myelin basic protein promoter exerts an enhanced cytotoxic effect in gliomas. Cancer Gene Therapy, 7, 739-748. doi:10.1038/sj.cgt.7700158

[35] Komata, T., Kondo, Y., Kanzawa, T., Ito, H., Hirohata, S., Koga, S., Sumiyoshi, H., Takakura, M., Inoue, M., Barna, B.P., Germano, I.M., Kyo, S. and Kondo, S. (2002) Caspase-8 gene therapy using the human telomerase reverse transcriptase promoter for malignant glioma cells. Human Gene Therapy, 13, 1015-1025. doi:10.1089/104303402753812421

[36] Yawata, T., Maeda, Y., Okiku, M., Ishida, E., Ikenaka, K. and Shimizu, K. (2011) Identification and functional characterization of glioma-specific promoters and their application in suicide gene therapy. Journal of Neurooncology, 104, 497-507. doi:10.1007/s11060-010-0522-0 